\title{
Taking the MDGs Beyond 2015: Hasten Slowly
}

\author{
Jan Vandemoortele and Enrique Delamonica
}

\begin{abstract}
The authors advise to hasten slowly in defining the successor framework to the MDGs. The review of progress in 2010 should not be intermingled with the intergovernmental discussions about the post-2015 framework. The latter should not start until a UN panel of Eminent Persons has prepared a set of thoughtful options and suggestions. The worst decision would be to keep the same MDGs and add new Goals and more Targets. The panel will have to address the following topics: (a) new structure; (b) new Targets; (c) collective nature of global Targets; (d) type of benchmarks; (e) new time horizon; and (f) disaggregated monitoring. The world will miss the MDGs largely because disparities within the majority of countries have grown to the point of slowing down national progress. In order to overcome the 'tyranny of averages', this article proposes a method of incorporating equity in national statistics.
\end{abstract}

\begin{abstract}
1 Hasten slowly
The Millennium Development Goals (MDGs)

have been tremendously successful in galvanising political leaders, civil society organisations, private sector actors, the media and donors, in the pursuit of human development. The architects of the MDGs never expected their support to spread so broad and so wide. As their deadline draws closer, calls for preparing the post-2015 period are being made with greater frequency and renewed urgency. Several actors are determined to shape the new framework and believe that early proposals will make most impact.
\end{abstract}

It would be ill-advised, however, to rush towards a new set of Targets for the post-2015 era. A considerable amount of work is required beforehand. It would be a grave mistake to take for granted the continued support for the current set of Goals and Targets beyond 2015 without responding to the many concerns and criticism voiced by several stakeholders, observers and analysts. They are valid and must be addressed. The worst option would be to simply keep the same MDGs and set new Targets with a new timeline.

The intergovernmental process for preparing the post-2015 period should not be intermingled with the review of progress in 2010. That review should focus on global progress towards global Targets. Regarding the post-2015 Targets, a UN panel of Eminent Persons should be established to prepare a set of intelligent and feasible options and suggestions. The panel's work would inform the intergovernmental debate about the post-2015 framework that would kick off in 2012. Apart from its regional and gender balance, the panel should include representatives from the worlds of policymaking, academia, development practice, civil society and the media.

By taking a 'big tent' approach, the panel's consultations would yield a range of options and possibilities that capture the views of a wide array of stakeholders. The process must be led by the stakeholders from developing countries; not by those from donor countries as is usually the case. Collins (2005: 24), a best-selling author on leadership, writes:

... those who fund the social sectors can bring an assumption of 'fair exchange' that is highly dysfunctional: if we give you money, we are entitled to tell you how to use that money. ${ }^{1}$

The degree of donorship must be reduced if the successor Targets to the MDGs are to emerge 
from a genuine partnership among equals. Compared with trade and other financial flows, foreign aid is something of an overblown sideshow. The international development agenda is often dominated by donor-centric perceptions of reality.

Huxley (1955) wrote:

Knowledge is acquired when we succeed in fitting a new experience into the system of concepts based upon old experiences. Understanding comes when we liberate ourselves from the old and so make possible a direct, unmediated contact with the new.

The aim of this article is to help alter the outlook of the MDGs from knowledge to understanding.

\section{Unconventional wisdom}

The MDGs have been misinterpreted, misused and misappropriated. Misinterpreted as national Targets; misused as a donor-centric view of development; and misappropriated as a call for faster growth or for more aid. Indeed, the MDGs have been misconstrued and distorted by different groups to suit their own purpose.

A recent paper of the Center for Global Development exemplifies some of these points. Severino and Ray (2009: 10) state that:

By aiming for targets [i.e. the MDGs] that are out of reach from the neediest countries' public authorities, the 'international community' (i.e. donor nations) has therefore accepted to substitute itself to some states in the provision of basic social services through long-term financial transfers.

The perception is widespread that unless all countries achieve the same global Targets, the world will not meet them. This view is incorrect. The MDGs are to be achieved collectively, not necessarily individually. The MDGs are global Targets; they do not need to be achieved in each and every country.

The misinterpretation of the MDGs as one-sizefits-all Targets has set the bar for sub-Saharan African countries unrealistically high. This has reinforced the perception of Afro-pessimism among development practitioners, policymakers and in the media. It begs the question whether Africa is missing the Targets or whether the world is missing the point. It is regrettable that some quarters use the MDGs to depict Africa as a failure so as to gain support for a particular agenda or argument.

Furthermore, the MDGs express ends of development; not means. They never aimed to prescribe a particular development strategy or policy framework. Yet, several quarters have tried to misappropriate the MDGs to gain support for their specific agenda - especially for faster economic growth and for more aid.

Bourguignon et al. (2008: 23), for instance, conclude:

... most developing countries were lagging behind $[\ldots]$. In middle-income countries, and in those countries with fast growth, filling these gaps may be essentially a question of implementing the adequate MDG-oriented policies. In other countries, accelerating growth and generating budget resources may be as important as MDG policies themselves. From that point of view, the focus of the international development community on Sub-Saharan Africa is fully justified.

It is not the first time that international Goals are misappropriated. In 2000, a joint publication by the United Nations, Organisation for Economic Co-operation and Development (OECD), International Monetary Fund (IMF) and World Bank reviewed progress towards the seven international development Goals that had been adopted by the OECD Development Assistance Committee (DAC) in 1996. Civil society organisations quickly rebranded the booklet from A Better World for All to Bretton Woods for All because they understood that a certain agenda had misappropriated the international Goals. The sections that summarised global progress on each of the seven Goals were not problematic; it was the closing section entitled 'What it will take to achieve the goals' that was unacceptable. Similarly, Kanbur (2009: 4) shows how the original set of reforms that Williamson coined as the 'Washington Consensus' was distorted to represent 'one side of an ideological divide which structured much of the development discourse in the 1990s'.

'Evidence-based' policymaking has recently emerged as jargon in the development debate 
(Davies 2004). It merits a pause to reflect on its meaning. Does it mean that in the past, policies were made by people who were driven by emotions or beliefs and solely motivated by selfinterest? Does it mean that policies are now made by rational and enlightened leaders; people who are no longer influenced by experience, context, politics or self-interest?

'Neuroeconomists' ${ }^{\text {'2 }}$ understand that human beings wear lenses that colour their perception and interpretation of reality. It would be naive to think that such lenses no longer exist. It is a fallacy to pretend that there is a single way of perceiving and interpreting reality. Hence, evidence-based policymaking can be a euphemism for misappropriating the policy debate by imposing a certain worldview on everyone else. Moreover, the argument that politics can be taken out of the process of policymaking is inconsistent with the promotion of multi-party democracy in developing and transition countries.

Having an ideology or believing in a particular theory is not dangerous. What is dangerous and potentially deceptive is to pretend not to be influenced by a particular theory or ideology, while hiding behind the false neutrality of socalled 'evidence-based' analysis. It is utopian to pretend that politics no longer matter; that policymaking can be based on rational analyses and an objective interpretation of reality.

The Commission on the Social Determinants of Health puts it as follows:

Traditional hierarchies of evidence (which put randomized controlled trials and laboratory experiments at the top) generally do not work for research on the social determinants of health. Rather, evidence needs to be judged on fitness for purpose - that is, does it convincingly answer the question asked.

Evidence is only one part of what swings policy decisions. (WHO 2008: 34)

The call for evidence-based policymaking is often accompanied by an emphasis on quantitative analysis. Statistics, however, have been used before to promote a particular theory or ideology. It was a mathematician turned philosopher who coined the term 'misplaced concreteness'. Whitehead (1925) argued that concepts such as aggregates and averages facilitate the comprehension of reality in all its complexity. However, one can easily forget that aggregates and averages are concepts that exist only in the human mind; they do not exist in reality.

Misplaced concreteness is to pretend that one is dealing with concrete persons or situations when, in fact, one deals with abstractions of reality. The danger of misplaced concreteness occurs when conclusions are drawn based on deductions from such abstractions, while believing that they are based on observations of concrete realities. Then, misplaced concreteness becomes an obstacle to gaining understanding over knowledge.

A case of misplaced concreteness unfolded in Kenya in the early 1980s. It was the era of structural adjustment when user fees for public utilities and basic social services were introduced around the world. Kenya was considering fees at public water points. The economists at the Ministry of Finance (including several foreign advisers) set about to develop an appropriate scheme. Some raised concerns about its impact on poor people. After lengthy discussions, it was agreed to introduce the water fee only in those districts where the average household income exceeded a certain threshold. When the utilisation rate of public water points dropped dramatically in the wake of the fee introduction, the economists in Nairobi were baffled. How could a small nominal fee have such a large impact? Their data showed that the average household income was more than adequate to cover this small expense. They failed to understand that the average household income was an abstraction of reality. It did not have any practical meaning to most women who had to pay the water fee. To them, the concept of an average household income did not correspond with the daily reality they faced, whereas the payment of the water fee represented a very concrete reality.

\section{Six areas of concern}

Before taking the MDGs beyond 2015, several aspects of their current formulation need to be examined and modified. They include:

(a) reshaping the structure of the Goals and Targets; (b) including new quantitative Targets;

(c) interpreting global Targets as collective ones;

(d) carefully choosing the type of benchmarks;

(e) fixing a new time horizon; and (f) monitoring beyond the national average. 


\section{(a) New structure}

The current set of MDGs has three healthrelated Goals (i.e. child mortality, maternal health, infectious diseases). They could be collapsed into one overall health Goal, thereby making space for the inclusion of other areas of concern. The current set of MDGs also includes two overlapping Targets, i.e. countries that achieve universal primary education automatically comply with the Target on gender equality in basic education. Such overlaps are unnecessary and ultimately unfair. Several observers have also criticised the poor coverage of gender equality and of environmental sustainability in the current set of MDGs.

\section{(b) New Targets}

The natural tendency is to add more Goals and new Targets. Candidates range from climate change to secondary education, quality of education, human rights, infrastructure, economic growth, good governance, security and others. But by adding more Targets, one diminishes the capacity of the MDGs to be understood intuitively and communicated easily with the general public. The number of Goals and Targets must be kept to a minimum. No matter their number, a set of Targets can never cover the many dimensions of human development in an adequate manner. Any belief in the perfectibility of the MDGs would be illusory. The MDGs were not conceived as a comprehensive or near-perfect expression of the complexity of human development. Rather, they offer a version of it that can easily be understood by a general audience. Most stakeholders value this branding and agree that it deserves to be protected. The MDGs have caught on so well because of their concise and measurable nature. Therefore, defining the content of the post-2015 set will demand tough choices. A strong but fair gatekeeper will be called for; because 'less is more'.

\section{(c) Collective nature of global Targets}

Global Targets apply at the global level. Unfortunately, the global MDG canon has turned them into yardsticks for measuring and judging performance at the national level. In doing so, the MDG debate suffers from misplaced concreteness. Their interpretation as one-sizefits-all Targets abstracts away the historical background of each country as well as her political system, natural endowment, geography, internal divisions and other challenges. The post-
2015 Targets must guard against the misconception that global Targets automatically serve as national Targets.

\section{(d) Type of benchmarks}

Performance can be measured according to absolute or relative benchmarks. Both are valid but none gives a complete picture. Most MDGs are expressed in relative terms, e.g. reducing poverty by half; cutting infant mortality by twothirds; slashing maternal mortality by threequarters. Since proportional changes tend to be inversely related to the initial situation, the misinterpretation of the MDGs as one-size-fitsall Targets puts the least developed and the lowincome countries at a disadvantage

(Vandemoortele 2009). This has led to a form of unconcealed discrimination of countries with low levels of human development. Global Goals and Targets have earlier been expressed in either absolute terms or as combined relative and absolute benchmarks. The post-2015 Goals and Targets will have to consider the implications of selecting a particular type of benchmark.

\section{(e) New time horizon}

An important detail that has been overlooked by many observers is that the Millennium Declaration (UN 2000) does not spell out the period over which the numerical Targets have to be achieved. It mentions the deadline year (mostly 2015) but relative benchmarks need a base year too. Since the world leaders could not agree on this, they concealed their disagreement by remaining silent about the period. The architects of the MDGs decided to take 1990 as the baseline year, based on historical trends at the global level. But as the MDGs came into being in 2001, there has been confusion as to whether they are to be achieved between 2000 and 2015 or over the period 1990-2015. The post-2015 Targets will need to be clear about the baseline year and the period over which they are to be achieved. They will have to weigh the pros and cons of short- versus long-term Targets. Whereas most dimensions of human development do not change significantly over the short-term, long-term Targets suffer from weak political accountability, because their deadline will not occur on the watch of the current governments. Intermediate Targets can compensate for this disadvantage (Vandemoortele 2008). Finally, the selection of the time horizon will need to take into account the usual three-five year time lag in obtaining global statistics. 


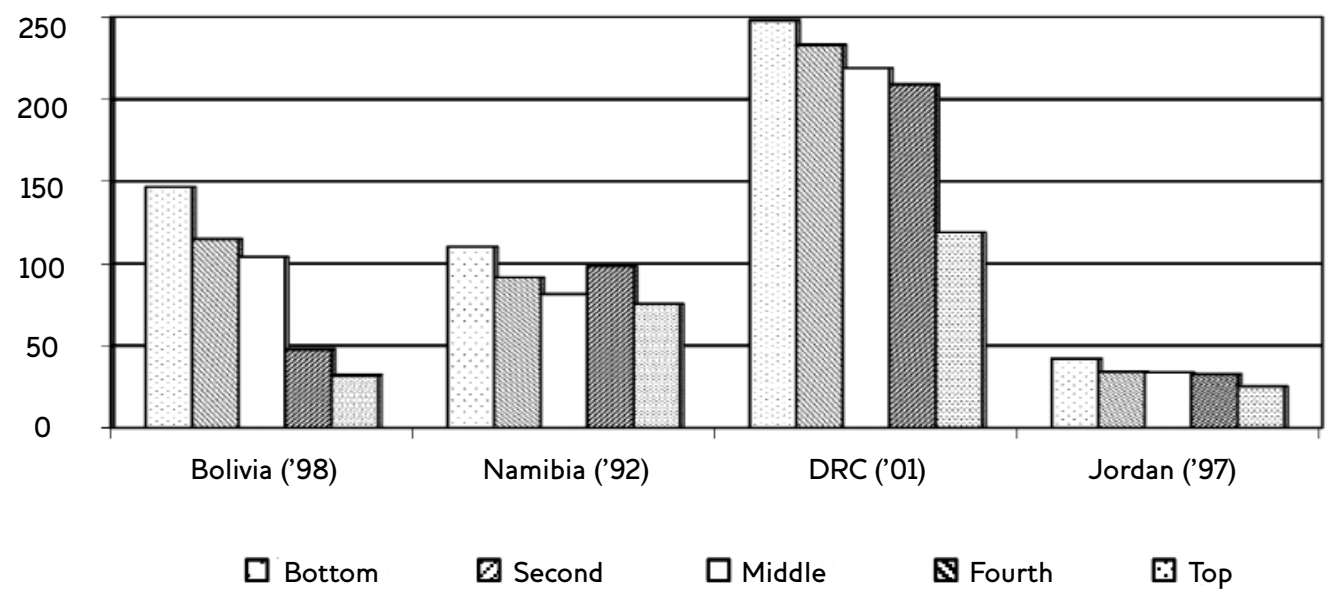

\section{(f) Disaggregated monitoring}

The world will not meet the MDGs largely because disparities within the majority of countries have grown to the point of slowing down national progress. Monitoring must bring this to the fore. The MDG Indicator for measuring equity - i.e. the 'share of the poorest quintile in national consumption' - covers it only partially. Moreover, it is seldom mentioned in the many MDG monitoring reports. The growing availability of disaggregated data makes it possible to adjust key national statistics for equity. Given its critical importance for achieving the MDGs and for realising pro-poor growth, the remainder of the article presents a concrete proposal for moving forward on disaggregated monitoring.

\section{Equity-adjusted national statistics}

Measurement matters because it influences action. When the nature and extent of poverty are unknown, it is unlikely that society will take strong action to reduce it. The same applies for equity. Societies measure things that are considered important. If something is not counted, it typically means that it does not count. Since a separate Indicator for equity proved insufficient to bring disparities to the fore, our proposal seeks to embed equity within existing Indicators. It is illustrated at the hand of quintilespecific data on under-five mortality rate (U5MR), which is among the more robust MDG Indicators.

Different groups in society have typically different levels of social and economic wellbeing. Data confirm that social Indicators vary considerably across groups within countries. Thus, national statistics do not only reveal; they also conceal. Some call it the 'fallacy of the mean'; others put it more strongly as the 'tyranny of averages'.

Recent surveys - especially the Demographic and Health Surveys (DHS) - provide disaggregated data. They have generated information by wealth quintile (i.e. one-fifth of the population) for numerous countries. The grouping of households is not based on income or consumption, which are notoriously difficult to measure. Instead, it is based on household assets that can be readily observed - such as the possession of a bicycle or a radio, electricity or water connections, the size and the type of construction materials of the dwelling (Filmer and Pritchett 2001).

\subsection{Patterns of disparities}

Data for most countries indicate a consistent association between household wealth and the level of human development. The U5MR declines steadily across quintiles; but according to different patterns. In Figure 1, the gradient for Bolivia, for instance, is steeper than for Namibia. Although both countries have a similar national U5MR value, the degree of representativeness of the national statistic is considerably less in the former than in the latter. The children in the bottom quintile in Bolivia are considerably worse off than the national U5MR statistic suggests. Children in the top quintile in Bolivia, on the other hand, face a much smaller risk of premature death than their counterparts in Namibia. 
Table 1 Quintile-specific weights

\begin{tabular}{lll}
\hline Quintile & Un-adjusted weight (\%) & Equity-adjusted weight (\%) \\
\hline Bottom & 20 & 30 \\
Second & 20 & 25 \\
Middle & 20 & 20 \\
Fourth & 20 & 15 \\
Top & 20 & 10 \\
Total & 100 & 100 \\
\hline
\end{tabular}

The Democratic Republic of Congo displays a typical pattern of many of the least developed countries, namely a moderate gradient across the lowest four quintiles with a sharp drop for the top quintile. Jordan, on the other hand, shows an egalitarian pattern.

In short, there are different patterns to distribute a national progress across the population. At one extreme, it can be limited to improvements for the better-off people, i.e. through a low-equity approach. At the other extreme, progress can be driven by ameliorations in the situation of the worse-off people, i.e. through a high-equity scenario. Several combinations lie in between.

\subsection{Proposed method}

Adjusting a national statistic for disparities can be done by weighing the quintile-specific values in a way that accords priority to progress for the lower quintiles. According to standard practice, the national average gives equal weights to all quintiles. ${ }^{3}$ Table 1 proposes weights that accord a higher priority to the lower quintiles.

It is not unreasonable to give the bottom quintile a 30 per cent weight and the top quintile a 10 per cent weight, implying that progress for the lowest quintile accounts for three times more than the same progress made for the highest quintile. Other quintiles receive intermediate weights on a sliding scale, so that they add up to 100 per cent.

Take a country with an average U5MR value of 100 per 1,000 live births that is characterised by a moderate gradient across quintiles, as depicted under the baseline scenario in Figure 2. Assume that the country manages to reduce her national U5MR from 100 to 70 . Figure 2 depicts three possible scenarios. First, the low-equity scenario

Figure 2 U5MR by quintile - different scenarios

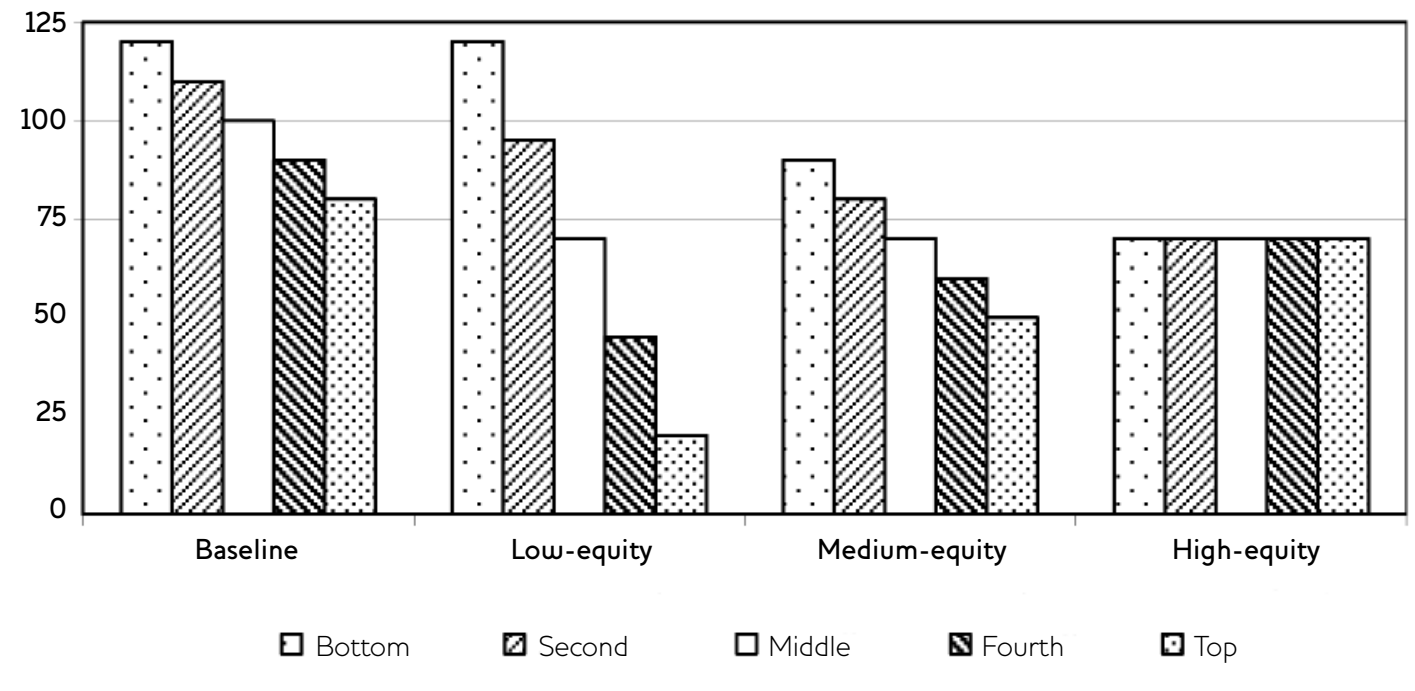


Table 2 National U5MR statistics by scenario

\begin{tabular}{lll}
\hline Scenario & Using un-adjusted weights & Using equity-adjusted weights \\
\hline Low-equity & 70 & 83 \\
Medium-equity & 70 & 75 \\
High-equity & 70 & 70 \\
\hline
\end{tabular}

implies that most of the gains accrue to the upper quintiles. The gradient across quintiles becomes markedly steeper than in the baseline year. Second, the medium-equity scenario reduces U5MR by 30 points for all quintiles. The gradient across quintiles remains the same as in the baseline year. Third, the high-equity scenario equalises the U5MR for all quintiles to 70; implying that the lowest quintiles benefit the most. The gradient across quintiles disappears.

Under each of the three scenarios, the quintiles face very different realities, yet this is not captured by the national U5MR statistic. The U5MR for the bottom quintile ranges from 120 to 70 ; that for the top quintile varies between 70 and 20. Nonetheless, the un-adjusted national U5MR statistic is the same under the three scenarios, namely 70. Thus, it cannot be known from the national statistic how equitable progress has been.

By using equity-adjusted weights, however, the national U5MR statistic will indicate whether progress is distributed equitably or not. The more equitable the pattern of progress, the better the national statistic becomes. By applying the equity-adjusted weights given in Table 1, the low-equity scenario yields a national U5MR statistic of 83. This is about one-fifth higher than that for the high-equity scenario. The medium-equity scenario results in a national U5MR value of 75; as shown in Table 2 .

Equity-adjusted weights imply that countries that follow a low-equity scenario will register a higher national U5MR value. Hence, their ranking will be different from the standard ranking.

Six other methods have been considered. First, the U5MR for the bottom quintile can be used as summary measure for equitable progress. This is equivalent to placing the weight of 100 per cent on the bottom quintile and weights of zero (0) to the other quintiles. While it is a good Indicator of the situation of the most disadvantaged, it fails to capture the disparities within the society at large. The second method is inspired by the 'vast majority income approach' proposed by Shaikh and Ragab (2007). It is equivalent to using a weight of zero for the top quintile and a weight of 25 per cent each for the other quintiles. This method overlooks the disparities within the bottom four quintiles. The third method is the 'ratio gap'. It measures the ratio between the top and bottom quintiles and multiplies the national average by that ratio to adjust the national U5MR statistic. This method also fails to capture the intermediate quintiles. In addition, it yields adjusted U5MR values with little appeal and intuitive understanding because they are exceedingly high. The fourth method is inspired by Paes de Barros (forthcoming) and is based on 'excess' mortality. Excess for each quintile is calculated as the difference between the average U5MR and the quintile-specific U5MR. If the quintile-specific is lower than the national average, the excess is zero. The sum of the quintile-specific excesses is added to the national U5MR value to obtain the adjusted national statistic. As with the use of the 'ratio gap', most countries see their adjusted U5MR soar beyond typical levels. This method, while good at measuring the level of disparity, fails to capture the pattern of inequity in that it does not show from which quintiles 'excess' originates.

The fifth method calculates the geometric mean instead of the arithmetic average. The higher the level of inequity, the lower the geometric mean will be. However, U5MR is a negative outcome so that higher inequality should be reflected in a higher adjusted statistic. This can be fixed by calculating the difference between the geometric and arithmetic averages and adding the difference. However, such conversions obscure the results and make them less intuitive to understand. The sixth and final method adjusts the average U5MR with the concentration index; akin to Sen's (1976) approach for income 


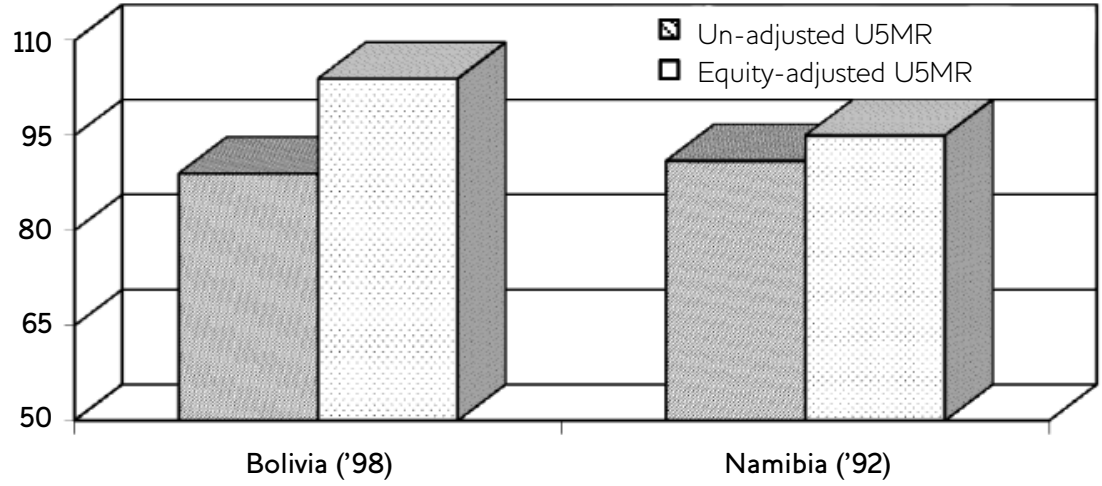

distribution. It also results in lower U5MR values for the most iniquitous countries, as the concentration index takes negative values in the presence of inequality. Again, this can be solved by conversions. The concentration index, however, is relatively small and thus leads to relatively small changes in the adjusted U5MRs, even for countries with large disparities.

A sensitivity analysis was performed on the database with weights of 25 and 35 per cent, respectively, for the bottom quintile. It shows that the outcome differs proportionately to the change in weights. When the difference in weights is large, the impact on the adjusted U5MR statistic is large. A small difference in weights does not really impact significantly on the equity-adjusted statistic. Thus, adjusted weights that start with 30 per cent for the bottom quintile seem justified.

\subsection{Data and analyses}

Quintile-specific U5MR estimates are readily available from DHS sources. Our sample covers 63 countries. Several countries have two or more surveys, so that a total of 133 observations are included in our sample. ${ }^{4}$ The equity-adjusted U5MR values are compared with the un-adjusted statistics to assess different equity patterns across countries and over time.

The difference between the un-adjusted and the equity-adjusted U5MR values for the 133 observations in the sample averages 8 per cent. It ranges from 19 per cent in Peru to -0.9 per cent in Chad. ${ }^{5}$ The top-ten countries in terms of disparities include Peru, Bolivia, South Africa, Egypt, Vietnam, the Philippines, Turkey, the Dominican Republic, Indonesia and Nicaragua.
As mentioned earlier, Bolivia and Namibia have the same national U5MR value but with marked differences in gradients across quintiles. Figure 3 shows that Bolivia sees an increase by 17 per cent in its U5MR statistic when adjusted for equity, whereas Namibia's statistic increases by a mere 3 per cent. The equity-adjusted U5MR for the former is 10 per cent higher than for the latter. Bolivia's entrenched inequality is thus made explicit from its equity-adjusted national statistic; something the standard statistic does not reveal.

Of the 63 countries in the sample, 46 have trend data. Of those, the majority displays either widening disparities over time or no consistent trend. Only two countries (Bolivia and Ghana) show a distinct tendency towards less inequity. The ranking of countries changes considerably. About half of the 63 countries in the sample see a change in their ranking with the equityadjusted statistics - up to five places difference. Proportionately more countries in Latin America see their ranking worsen than those in subSaharan Africa.

\section{Conclusion}

This article recommends to hasten slowly in defining the post-2015 framework. It will be vital for bilateral and multilateral aid agencies, international non-governmental organisations (NGOs) and think-tanks not to rush into defining the successor to the MDGs. Adequate consultations among the various stakeholders will be essential for maintaining the current level of support for a Target-driven approach to the international development agenda. The process must be led by the stakeholders from developing countries. ${ }^{6}$ 
The 2010 review must focus on global progress towards the global Goals. The intergovernmental discussions on the post-2015 framework should not start until a UN panel of Eminent Persons has prepared intelligent and feasible options for the post-2015 Targets. The worst decision would be to simply keep the same MDGs and set new Targets with a new timeline.

Apart from making a strong case for a Targetdriven approach to development, the panel will have to address the following areas: (a) new structure; (b) new Targets; (c) collective nature of global Targets; (d) type of benchmarks; (e) new time horizon; and (f) disaggregated monitoring.

Reducing disparities within countries emerges as the critical condition for meeting the MDGs by

\section{Notes}

1 It reportedly took the author longer to write the 36-page monograph Good to Great and the Social Sectors (Collins 2005) than it did to write his 300-page bestseller Good to Great: Why Some Companies Make the Leap ... and Others Don't (Collins 2001).

2 A term mentioned by Harford (2009: 60).

3 Equity-adjusted weights will differ by Indicator. The un-adjusted weights of 20 per cent per quintile for U5MR would assume that the fertility rate is uniform across quintiles. In reality, families in the lower quintiles tend to have more children so that their share in the under-five population will exceed 20 per cent. Hence, weights that

\section{References}

Abbé Pierre (1994) Testament, Paris: Bayard Editions

Bourguignon, F.; Bénassy-Quéré, A.; Dercon, S.; Estache, A.; Gunning, J.; Kanbur, R.; Klasen, S.; Maxwell, S.; Platteau, J.P. and Spadaro, A. (2008) 'Millennium Development Goals at Midpoint: Where Do We Stand?', paper written for DFID and the DG Development of the European Commission

Collins, J. (2005) Good to Great and the Social Sectors. Why Business Thinking is Not the Answer. A Monograph to Accompany 'Good to Great', Boulder: Random House
2015. Given the increased availability of disaggregated data it is now feasible to adjust key national statistics to reflect disparities within countries. The article proposes a straightforward method for embedding equity into national statistics on key dimensions of human development. The resulting change in the ranking of countries is likely to trigger a much needed focus on disparities.

The method is meant to keep watch over equity trends. It is likely to be criticised by mainstream statisticians and economists alike. Without dismissing the statistical caveats involved, league tables do catch the eye of political leaders. They have prompted local and global action in the pursuit of pro-poor outcomes. Such action will be vital for ensuring a future for the MDGs, or whatever they will be called beyond 2015 .

adjust for equity will have to be Indicatorspecific.

4 Data are available from the authors upon request (jan.vandemoortele@gmail.com).

5 The sole observation in the sample that does not show a downward sloping gradient in U5MR by wealth groups is Chad (2004). Between 1996 and 2004, the U5MR increased for the bottom and top quintiles, whereas it decreased for the other quintiles.

6 'Les solutions, il va falloir les chercher ensemble. Sinon, on s'épuisera à prévoir des aides aux pays en voie de développement' [The solutions will have to be sought together. If not, we will exhaust ourselves providing aid to poor countries] (Abbé Pierre 1994: 170).

Collins, J. (2001) Good to Great: Why Some Companies Make the Leap ... and Others Don't, New York: HarperBusiness

Davies, P. (2004) 'Is Evidence-Based Government Possible?', the Jerry Lee Lecture presented at the 4th Annual Campbell Collaboration Colloquium in Washington DC

Filmer, D. and Pritchett, L. (2001) 'Estimating Wealth Effects Without Expenditure Data Or Tears: An Application to Education Enrollments in States of India', Demography 38.1: 115-32

Harford, T. (2009) The Logic of Life, London: Abacus 
Huxley, A. (1955) 'Knowledge and Understanding', lecture given at the Vedanta Society of Southern California, 'Vedanta and the West'

Kanbur, R. (2009) The Co-evaluation of the Washington Consensus and the Economic Development Discourse, WP 2009-05, Ithaca: Department of Applied Economics and Management, Cornell University

OECD/DAC (1996) Shaping the 21st Century, Paris: Organisation for Economic Co-operation and Development/Development Assistance Committee

Paes de Barros, R. (forthcoming) Global Study on Child Poverty: Brazil Case Study, New York: United Nations Children's Fund (UNICEF)

Sen, A. (1976) 'Real National Income', Review of Economic Studies 43.1: 19-39

Severino, J.M. and Ray, O. (2009) The End of ODA: Death and Rebirth of a Global Public Policy, Working Paper 167, Washington DC: Center for Global Development

Shaikh, A. and Ragab, A. (2007) An International Comparison of the Incomes of the Vast Majority, New York: Schwartz Centre for Economic Analysis
United Nations (2000) Millennium Declaration, DPI/2163, New York: Department of Public Information

United Nations, Organisation for Economic Co-operation and Development (OECD), International Monetary Fund (IMF), World Bank (2000) A Better World for All, document presented at 'Geneva 2000', a conference to review progress on the Social Summit of 1995, New York: United Nations

Vandemoortele, J. (2009) 'The MDG Conundrum: Meeting the Targets Without Missing the Point', Development Policy Review 27.4: 355-71

Vandemoortele, J. (2008) 'Making Sense of the MDGs', Development 51.2: 220-7

Whitehead, A.N. (1925) An Enquiry Concerning the Principles of Natural Knowledge, Cambridge: Cambridge University Press

WHO (2008) Closing the Gap in a Generation: Health Equity Through Action on the Social Determinants of Health, Geneva: Commission on Social Determinants of Health, the World Health Organization 